\title{
Effect of Topical Administration of Tranexamic Acid in Reducing Post-Operative Bleeding after Off-Pump Coronary Artery Bypass Surgery-A Single Center Experience
}

\author{
Asraful Hoque ${ }^{1}$, Mauin Uddin ${ }^{2}$, Shahriar Moinuddin ${ }^{1}$ \\ ${ }^{1}$ Department of Cardiac Surgery, NIVCVD, Dhaka ${ }^{2}$ Department of Cardiac Surgery, \\ United Hospital Limited, Dhaka.
}

\begin{abstract}
:
Keywords: Coronary artery disease, Blood transfusion, Coronary artery bypass, Tranexamic acid, Haemorrhage.

Background: This study was designed to assess the role of topically applied tranexamic acid in pericardial cavity in reducing post operative bleeding.

Methods: This study is a non-randomized, double blinded, clinical trial, conducted in the Department of Cardiac Surgery, National Institute of Cardiovascular Diseases from January 2014 to December 2015 among the patients admitted for off pump coronary artery bypass (OPCAB) surgery. A total of 60 patients were recruited for the study and they were divided in two groups-30 patients in tranexamic acid group (Group I) and 30 patients in placebo group (Group II). On completion of the grafting, before closure of the sternum tranexamic acid $(2.5 \mathrm{~g} / 25 \mathrm{ml})$ or placebo $(25 \mathrm{ml}$ of saline) diluted in $100 \mathrm{ml}$ of warm saline $\left(37^{\circ} \mathrm{C}\right)$ was instilled into the pericardial cavity including the mediastinal tissues and left for 5 minutes. Total mediastinal bleeding and packed red cell transfusion were estimated in the postoperative period in both groups.

Results: There was no significant difference noted in baseline demographic data, basic clinical characteristics and preoperative coagulation profile between the 2 groups $(P>0.05)$. Total mediastinal bleeding and packed red cell transfusion in group I and group II patients was $421.67 \pm 70.32 v s$ $593.33 \pm 77.38 \mathrm{ml}, p<0.001$ and $0.87 \pm 0.0 .73$ units vs1.77 \pm 0.57 units, $p<0.001$. No patient required reoperation for bleeding and there was no incidence of myocardial infarction (MI), thrombo-embolism, deep venous thrombosis (DVT) or stroke in none of the patients in either group.

Conclusion: Topical application of tranexamic acid can significantly and safely reduce postoperative mediastinal bleeding. It also reduces whole blood transfusion requirements during immediate postoperative period among patients undergoing OPCAB surgery.
\end{abstract}

(Cardiovasc. j. 2017; 10(1): 52-55)

\section{Introduction:}

Bleeding is a common complication after coronary artery bypass (CABG). ${ }^{1}$ Excessive bleeding and blood transfusion play an important role in post-CABG mortality and morbidity. Fibrinolysis has been reported to be the cause of $25 \%$ to $45 \%$ of significant post CABG bleeding. ${ }^{2,3}$ Anti fibrinolytic agents (aprotinin, tranexamic acid, and å-aminocaproic acid) have been shown to inhibit fibrinolysis and thus reduce bleeding in cardiac surgery. ${ }^{4}$ Systemic administration of anti fibrinolytic agents has been commonly employed in the field of cardiac surgery. However, recent studies on large numbers of patients have raised growing concerns about the serious adverse effects observed following systemic administration of anti fibrinolytic agents. These complications include increased mortality, ${ }^{5}$ renal toxicity, ${ }^{4,6,7}$ anaphylactic reactions, ${ }^{8}$ graft vessel occlusion, ${ }^{9}$ the risk of myocardial infarction in highrisk cardiac surgery following aprotinin use. ${ }^{10}$ To overcome these effects topical application of anti fibrinolytic can be considered as a safe alternative. Moreover, it has been demonstrated that the topical application of the anti fibrinolytic drugs leads to a decreased serum level compared with their intravenous administration. Thus, some studies have investigated the effects of the topical application of these drugs in gynecological, dental, ear-nosethroat and cardiovascular surgery. ${ }^{11-14}$ So the present study was designed to investigate the topical

Address of Correspondence: Dr. Asraful Hoque. Department of Cardiac Surgery, NICVD, Dhaka, Bangladesh. e-mail-dr_asraf_sium@yahoo.com 
application of tranexamic acid in the pericardial cavity on post-operative blood loss in off-pump CABG.

\section{Methods:}

This study is a non-randomized, double blinded, clinical trial, conducted in the department of cardiac surgery, National Institute of Cardiovascular Diseases from January 2014 to December 2015 among the patients admitted for OPCAB surgery. A total 60 number of patients were enrolled for the study. They were randomly assigned in two groups30 patients in tranexamic acid group (Group I) and 30 patients in placebo group (Group II). On completion of the grafting, before closure of the sternum tranexamic acid $(2.5 \mathrm{~g} / 25 \mathrm{ml})$ or placebo (25 ml of saline) diluted in $100 \mathrm{ml}$ of warm saline $\left(37^{\circ} \mathrm{C}\right)$ was instilled into the pericardial cavity including the mediastinal tissues and left for 5 minutes. Then it was cleared out and sternum was closed. Data were collected using case record collection form from patient's admission up to the discharge of the patient from ICU. Statistical analysis was done using SPSS version 17.0 software.

There was no significant difference noted in baseline demographic data, basic clinical characteristics and preoperative coagulation profile between the 2 groups $(\mathrm{P}>0.05)$. All patients were pre-medicated with tablet midazolam $7.5 \mathrm{mg}$ orally the night before surgery. Injection Morphine sulphate $7.5 \mathrm{mg}$ intramuscularly (I.M.) and tablet Metoprolol $25 \mathrm{mg}$ per orally were given 1 hour before surgery. Standard anesthetic technique including induction, maintenance and recovery were being followed. A median sternotomy was done and at the same time Great saphenous vein and Internal mammary artery was harvested and prepared for the graft. The distal anastomosis with reverse saphenous venous graft was done with partial clamp of aorta. The drainage of the chest tubes were measured hourly and were removed when the total drainage volume of $<50 \mathrm{ml}$ over the previous 12 hours and of serous color. Uniform transfusion protocol was applied to all patients. Blood and blood components were administered only when the hematocrit level < $24 \%$ or the haemoglobin level d" $8.0 \mathrm{gm} / \mathrm{dl}$ in the postoperative period.

\section{Results:}

Both groups were compared according to their preoperative clinical and demographical characteristics and there were no significant statistical differences found between them. Similarly, there was no statistically significant difference among the two groups in preoperative hematological characteristics in terms of haematocrit, platelet count, INR, bleeding time and clotting time Table II (41.8 \pm 2.34 vs. $41.27 \pm 2.42 \%$, $\mathrm{p}=0.389 ; 237.5 \pm 35.05$ vs. $254 \pm 37.84 \times 10^{9} / \mathrm{cmm}$, $\mathrm{p}=0.085 ; 1.05 \pm 0.08$ vs. $1.05 \pm 0.1 \mathrm{sec}, \mathrm{p}=0.838$; $4.24 \pm 0.48$ vs. $4.24 \pm 0.5 \mathrm{~min}, \mathrm{p}=0.965$ and $5.89 \pm 0.42$ vs. $5.88 \pm 0.41 \mathrm{~min}, \mathrm{p}=0.958$ respectively).

Average amount of bleeding at 4 hours post operatively was $116.67 \pm 44.2 \mathrm{ml}$ in tranexamic acid group and $190 \pm 44.33 \mathrm{ml}$ in placebo group $(\mathrm{p}<0.01)$. Post operative mediastinal bleeding at 12 hours and at the end of chest tube removal were also significantly higher in placebo group than the study group (345 \pm 74.68 vs. $511.67 \pm 66.54 \mathrm{ml}, \mathrm{p}<0.01)$ and $(421.67 \pm 70.32$ vs. $593.33 \pm 77.38 \mathrm{ml}, \mathrm{p}<0.01)$ respectively. The average number of units of whole blood transfusion post operatively in study group and control group was $0.87 \pm 0.73$ units and $1.77 \pm 0.57$ units respectively $(\mathrm{p}<0.001)$. (1 unit= about 450 $\mathrm{ml})$. Although regarding transfusion of fresh frozen plasma (FFP), both the groups did not have significant difference (Group 1: $0.93 \pm 0.9$ vs. group $2: 1.2 \pm 0.76 ; \mathrm{p}=0.22)$. No patient required reoperation

Table-I

Distribution of the patients according to preoperative investigation profile

\begin{tabular}{lcccc}
\hline Investigation profile & \multicolumn{2}{c}{ Group of the patient } & Total & p-value \\
\cline { 2 - 3 } & Group I (n=30) & Group II (n=30) & & \\
\hline Haematocrit (\%) & $41.8 \pm 2.34$ & $41.27 \pm 2.42$ & $41.53 \pm 2.38$ & 0.389 \\
Platelet count (x10\%/cmm) & $237.5 \pm 35.05$ & $254.0 \pm 37.84$ & $245.75 \pm 37.11$ & 0.085 \\
INR & $1.05 \pm 0.08$ & $1.05 \pm 0.1$ & $1.05 \pm 0.09$ & 0.838 \\
Bleeding time (min) & $4.24 \pm 0.48$ & $4.24 \pm 0.5$ & $4.24 \pm 0.49$ & 0.965 \\
Clotting time (min) & $5.89 \pm 0.42$ & $5.88 \pm 0.41$ & $5.89 \pm 0.41$ & 0.958 \\
\hline
\end{tabular}

Data were analyzed using Student's t-Test and presented as mean \pm SD 
Table-II

Distribution of the patients according to Postoperative bleeding

\begin{tabular}{lcccc}
\hline Postoperative & \multicolumn{2}{c}{ Group of the patient } & Total & p-value \\
\cline { 2 - 3 } mediastinal bleeding & Group I $(\mathrm{n}=30)$ & Group II $(\mathrm{n}=30)$ & & \\
\hline At 4 hours $(\mathrm{ml})$ & $116.67 \pm 44.2$ & $190 \pm 44.33$ & $153.33 \pm 57.39$ & 0.000 \\
At 12 hours $(\mathrm{ml})$ & $345.00 \pm 74.68$ & $511.67 \pm 66.54$ & $428.33 \pm 109.45$ & 0.000 \\
Total bleeding $(\mathrm{ml})$ & $421.67 \pm 70.32$ & $593.33 \pm 77.38$ & $507.5 \pm 113.43$ & 0.000 \\
\hline
\end{tabular}

Data were analyzed using Student's t-Test and presented as mean \pm SD

Table-III

Distribution of the patients according to postoperative transfusion

\begin{tabular}{lcccc}
\hline Blood \& blood products & \multicolumn{2}{c}{ Group of the patient } & Total & p-value \\
\cline { 2 - 3 } & Group I (n=30) & Group II $(\mathrm{n}=30)$ & & \\
\hline Whole blood transfusion (units) & $0.87 \pm 0.73$ & $1.77 \pm 0.57$ & $1.32 \pm 0.79$ & .000 \\
FFP (units) & $0.93 \pm 0.9$ & $1.2 \pm 0.76$ & $1.07 \pm 0.84$ & 0.222 \\
\hline
\end{tabular}

Data were analyzed using Student's t-Test and presented as mean $\pm \mathrm{SD}$

for bleeding. There was no incidence of MI, thromboembolism, DVT or stroke.

\section{Discussion:}

In our study postoperative mediastinal bleeding at 4 hours, 12 hours in group I and group II patients were $116.67 \pm 44.2 \mathrm{ml}$ vs. $190 \pm 44.33 \mathrm{ml}(\mathrm{p}=0.000)$, $345 \pm 74.68 \mathrm{ml}$ vs. $511.67 \pm 66.54 \mathrm{ml}(\mathrm{p}=0.000)$ respectively. Total postoperative mediastinal bleeding was also significantly lower in tranexamic acid group than in placebo group (421.67 \pm 70.32 vs. $593.33 \pm 77.38 \mathrm{ml} ; \mathrm{p}=0.000$ ).

Baric and his colleagues reported cumulative blood loss within $24 \mathrm{~h} 633 \pm 343 \mathrm{ml}$ in tranexamic acid group and $903 \pm 733 \mathrm{ml}$ in placebo group. This study included patients undergoing coronary surgery, valve surgery and other cardiac surgeries. The tranexamic acid group received $2.5 \mathrm{gm}$ tranexamic acid in $250 \mathrm{ml}$ normal saline and the other group received $250 \mathrm{ml}$ of normal saline in the pericardial cavity and over the mediastinal tissue before median sternotomy closure. ${ }^{15}$

Hossein and his colleagues reported to enroll 71 patients in prospective study and grouped patients into two groups. In tranexamic acid group median of postoperative bleeding at the end of 24 hours was $366 \mathrm{ml}$ in comparison to $788 \mathrm{ml}$ in placebo group bearing significant difference. Though he used lower amount of tranexamic acid ( $1 \mathrm{gm})$ in his study. ${ }^{16}$

Nouraei and his colleagues reported total blood loss in Tranexamic acid group to be $313 \pm 173 \mathrm{ml}$ and
$454 \pm 268 \mathrm{ml}$ in control group $(\mathrm{p}<0.01)$. In the study tranexamic acid $(2 \mathrm{~g} / 20 \mathrm{~mL})$ or placebo $(20 \mathrm{~mL}$ of saline) was diluted in $500 \mathrm{~mL}$ of warm saline (37 ${ }^{\circ} \mathrm{C}$ ), poured into the pericardial cavity, and left for 5 min on completion of CABG (on pump) before sternotomy wound closure. The volume of blood loss were similar to our study. ${ }^{17}$

Aoki and his colleagues reported that the volume of blood loss in $24 \mathrm{~h}$ after intensive care unit admission was $492 \pm 180 \mathrm{ml}$ in control group and $303 \pm 112 \mathrm{ml}$ in tranexamic acid group $(\mathrm{p}<0.0001)$. They investigated 100 consecutive patients undergoing off-pump coronary artery bypass. In the study group $10 \mathrm{~mL}$ of a solution containing $1 \mathrm{~g}$ of tranexamic acid was sprayed into the pericardial cavity and mediastinum before the sternum was closed. Our study showed similar volume of blood loss. ${ }^{18}$

\section{Conclusion:}

The result of this study allows us to conclude that the topical application of tranexamic acid leads to reduction of blood loss after off-pump CABG procedure. In addition it decreases whole blood transfusion requirement after CABG surgery.

\section{Conflict of Interest - None.}

\section{References:}

1. Ozal E, Kuralay E, Bingöl H, Cingöz F, Ceylan S, Tatar $\mathrm{H}$. Does tranexamic acid reduce desmopressin induced hyper fibrinolysis? J Thorac Cardiovasc Surg 2002;123: 539-543. 
2. Fawzy H, Elmistekawy E, Bonneau D. Can local application of tranexamic acid reduce post-coronary bypass surgery blood loss? A randomized controlled trial, Journal of Cardiothoracic Surgery 2009; 4: 25.

3. Verska JJ, Lonser ER, Brewer LA. Predisposing factors and management of hemorrhage following open heart surgery. J Cardiovasc Surg 1972; 13: 361-368.

4. Henry DA, Carless PA, Moxey AJ. Anti-fibrinolytic use for minimising perioperative allogeneic blood transfusion, Cochrane Database Systemic Review CD 2007: 001886,

5. Mangano DT, Miao Y, Vuylsteke A. Mortality associated with aprotinin during 5 years following coronary artery bypass graft surgery. JAMA 2007; 297: 471-479.

6. Karkouti K, Wijeysundera DN, Yau TM. The independent association of massive blood loss with mortality in cardiac surgery. Transfusion 2004; 44: 1453-1462.

7. Brown JR, Birkmeyer NJ, O'Connor GT. Meta-analysis comparing the effectiveness and adverse outcomes of anti fibrinolytic agents in cardiac surgery. Circulation 2007; 115: 2801-2813.

8. Beierlein W, Scheule AM, Dietrich W, Ziemer G. Forty years of clinical aprotinin use: a review of 124 hypersensitivity reactions. Ann Thorac Surg 2005; 79: 741-748.9. Westaby S, Katsumata T. Aprotinin and vein graft occlusion - the controversy continues. $J$ Thorac Cardiovasc Surg 1998; 116: 731-733.

10. Fergusson DA, Hebert PC, Mazer CD. A comparison of aprotinin and lysine analogues in high-risk cardiac surgery. N Engl J Med 2008; 358: 2319-2331.

11. Sarris I, Arafa A, Konaris L, Kadir RA. Topical use of tranexamic acid to control perioperative local bleeding in gynaecology patients with clotting disorders: Two cases. Haemophilia 2007; 13: 115-116.

12. Carter G, Goss A. Tranexamic acid mouthwash -A prospective randomized study of a 2-day regimen vs 5 day regimen to prevent postoperative bleeding in anticoagulated patients requiring dental extractions. Int J Oral Maxillofac Surg 2003; 32:504-507.

13. Athanasiadis T, Beule AG, Wormald PJ. Effects of topical antifibrinolytics in endoscopic sinus surgery: A pilot randomized controlled trial. Am J Rhinol 2007; 21:737-742.

14. Abul-Azm A, Abdullah KM. Effect of topical tranexamic acid in open heart surgery. Eur $J$ Anaesthesiol 2006; 23: 380-384.

15. Baric D, Biocina B, Unic D, Sutlic Z, Rudez I, Vrca VB, et al. Topical use of antifibrinolytic agents reduces postoperative bleeding: A double-blind, prospective, randomized study. Eur J Cardiothorac Surg 2007; 31: 366-371.

16. Hosseini H, Rahimianfar AA, Abdollahi MH, Moshtaghiyoon MH, Haddadzadeh M, Fekri, et al. Evaluations of topical application of tranexamic acid on post-operative blood loss in off-pump coronary artery bypass surgery. Saudi J Anaesth 2014; 8(2):224-228.

17. Nouraei M, Baradari A, Ghafari R, Habibi M,Emami A, Sharifi N. Decreasing blood loss and theneed for transfusion after CABG surgery: A doubleblindrandomized clinical trial of topical tranexamic acid. Turk J Med Sci 2013; 43(2):273-8.

18. Aoki M, Okawa Y, Goto Y, Ogawa S, Baba H. Local administration of tranexamic acid in off-pump coronary artery bypass. Asian Cardiovasc Thorac Ann 2012; 20(6):658-662. 